\title{
Um debate socioeconômico sobre a legalização do aborto: primeiros resultados
}

\author{
Bárbara OLIVEIRA ${ }^{(1)}$ \\ Samara Jamile MENDES(1) \\ ${ }^{(1)}$ Faculdade de Saúde Pública, Universidade de São Paulo - USP, São Paulo, SP, Brasil.
}

Recebido: 28 jan 2019 Aceito: 10 fev 2019

Autor de

correspondência:

barbara.oliveira75@gmail.com

Conflito de interesses: Os autores declaram não haver nenhum interesse profissional ou pessoal que possa gerar conflito de interesses em relação a este manuscrito.

\section{Resumo}

Historicamente, o aborto induzido sempre esteve presente na sociedade ocidental. Os greco-romanos, que entendiam que o aborto poderia ser realizado desde que se obtivesse o consentimento do pai, até o pós revolução francesa, onde, devido aos avanços médico-científicos atrelados a necessidades do Estado (índices maiores de natalidade), o feto deixa de ser considerado como o apêndice da mãe e seu nascimento se torna de interesse do Estado. Aliado a isso, a crescente influência das tradições e valores católicos à legislação do Estado faz com que o aborto passe a ser considerado uma prática ilegal, sendo estabelecidas políticas punitivas a mulheres que realizassem tal prática. Com o movimento feminista, mais proeminente a partir da década de 1960, existe uma crescente discussão sobre as decisões relacionadas a posse do corpo feminino, e àquelas ligadas a sexualidade e a maternidade, principalmente sobre gestar ou não um feto. Neste movimento, o entendimento do abortamento como uma questão da saúde da mulher se estabelece e este é a base para que hoje se trate aborto como uma questão de saúde pública no Brasil, em detrimento das questões morais exploradas por alguns grupos da sociedade. Mesmo com a expressiva produção científica acerca da prática do aborto, perfil socioeconômico de quem realiza, dados demográficos, consequências e ética, a literatura existe a respeito dos possíveis impactos econômicos positivos ou negativos da legalização do aborto ainda é pequena. Objetivo: o objetivo deste estudo é analisar a produção científica disponível acerca dos impactos socioeconômicos da legalização do aborto. Método: para cumprir os objetivos deste artigo, foi realizada uma revisão integrativa, cuja questão norteadora será: como a legalização do aborto pode impactar socioeconomicamente os sistemas de saúde? Foram utilizadas neste estudo as seguintes bases de dados: Scopus, PubMed (Publicações Médicas). As palavras-chave foram escolhidas a partir de consultas ao DeCs (Descritores em Ciências da Saúde) para bases de dados latino-americanas e ao MeSH (Medical Subject Headings) para bases de maior alcance. Por fim, os descritores utilizados foram: abortion, induced abortion, economics, costs and cost analysis e cost-benefit analysis, health e health system, buscadas em um primeiro momento individualmente para entendimento da quantidade de produção científica disponível de cada descritor e depois, utilizando a técnica do funil construção da sintaxe de busca. Não houve restrição 
de idioma e nem de período na busca de dados. Resultados: a partir das buscas individuais e exercícios de construção de sintaxe, nota-se que a sintaxe que melhor atende aos objetivos deste estudo é: ((("abortion, induced'[MeSH Terms] OR ("abortion"[A// Fields] AND "induced"[A// Fields]) OR "induced abortion"[A/l Fields] OR "abortion"[A/l Fields]) AND ("economics"[Subheading] OR "economics"[A/l Fields] OR "economics"[MeSH Terms])) AND ("costs and cost analysis"[MeSH Terms] OR ("costs"[A/l Fields] AND "cost"[A/l Fields] AND "analysis"[A/l Fields]) OR "costs and cost analysis"[A/l Fields])) AND ("cost-benefit analysis"[MeSH Terms] OR ("cost-benefit" [A// Fields $]$ AND "analysis"[A// Fields]) OR "cost-benefit analysis"[A/l Fields] OR ("cost'[A/l Fields] AND "benefit" $[$ All Fields] $A N D$ "analysis"[A/l Fields]) OR "cost benefit analysis"[A/l Fields])) AND ((Heath[All Fields] AND System[All Fields]) OR ("health"[MeSH Terms] OR "health" $[$ Al/ Fields $]))$ para o PubMed com 158 artigos encontrados e ( TITLE-ABS$\operatorname{KEY}($ ( ( ( ( ( abortion) AND economics) AND (costs AND cost AND analysis )) $A N D$ cost-benefit AND analysis )) ) AND TITLE-ABS-KEY ( ( health OR health AND system )) ) para a base de dados Scopus com 26 artigos. Busca semelhante foi realizada na base de dados Lilacs que retornou apenas 1 artigo para inclusão. Considerando todas as bases pesquisadas, partiu-se do número de 185 artigos disponíveis na literatura internacional que atendem à sintaxe descrita. Após a triagem dos artigos que foram encontrados por meio da estratégia de busca, foram selecionados os artigos a serem incluídos na revisão integrativa de acordo com os seguintes critérios de inclusão: (a) abordar a discussão acerca do aborto do ponto vista sócio-econômico; (b) evidenciar custos sobre a legalização do aborto para os países em que foram realizadas as pesquisas; (c) evidenciar os custos para os sistemas de saúde da prática do aborto ilegal; e exclusão: (a) artigos que não incluam a perspectiva econômica ao abordar o tema aborto; (b) artigos que abordem a temática do aborto sob o ponto de vista puramente técnico; (c) artigos que abordem apenas diferenças de eficiência ou custo de diferentes métodos de realização do aborto; (d) artigos que sejam em outras línguas que não sejam em português, nem inglês ou espanhol. Dos 185 artigos, nove artigos foram excluídos por serem duplicatas, um por não atender o critério de idioma, 94 artigos por não abordarem o tema aborto e 27 por não possuírem o ponto de vista econômico em sua abordagem. Existem outros 26 artigos classificados como indefinidos por não possuírem abstract nem artigo disponíveis nas bases de dados. Nas análises preliminares já é possível notar que a produção científica acerca do aborto não é recente, com os primeiros artigos datando de 1968, porém, ocorreu aumento significativo de publicações nos últimos 10 anos, com 45\% das 185 publicações entre 2008 e 2018 e $25 \%$ do total das publicações entre 2014 e 2018, sendo que as principais revistas a publicar o tema do aborto são revistas de obstetrícia e ginecologia. Além disso, grande parte dos artigos, especialmente em países onde o abordo já descriminalizado traz análises de custo-benefício de diferentes métodos abortivos.

Descritores: Aborto; Custos e Análise de Custo; Saúde; Sistemas de Saúde. 